\title{
Two-Dimensional Surface River Flow Patterns Measured With Paired RiverSondes
}

\author{
Calvin C. Teague, Donald E. Barrick, and Peter M. Lilleboe \\ CODAR Ocean Sensors, Ltd. \\ 1914 Plymouth Street \\ Mountain View, CA 94043 USA \\ (408) 773-8240 \\ cal@codar.com,don@codar.com, pete@codar.com
}

\author{
Ralph T. Cheng \\ U. S. Geological Survey \\ 345 Middlefield Road \\ Menlo Park, CA 94025 \\ (650) 329-4500 \\ rtcheng@usgs.gov
}

\begin{abstract}
Two RiverSondes were operated simultaneously in close proximity in order to provide a two-dimensional map of river surface velocity. The initial test was carried out at Threemile Slough in central California. The two radars were installed about $135 \mathrm{~m}$ apart on the same bank of the channel. Each radar used a 3-yagi antenna array and determined signal directions using direction finding. The slough is approximately $200 \mathrm{~m}$ wide, and each radar processed data out to about $300 \mathrm{~m}$, with a range resolution of $15 \mathrm{~m}$ and an angular resolution of 1 degree. Overlapping radial vector data from the two radars were combined to produce total current vectors at a grid spacing of $20 \mathrm{~m}$, with updates every 5 minutes. The river flow in the region, which has a maximum velocity of about $0.8 \mathrm{~m} / \mathrm{s}$, is tidally driven with flow reversals every 6 hours, and complex flow patterns were seen during flow reversal. The system performed well with minimal mutual interference. The ability to provide continuous, non-contact two-dimensional river surface flow measurements will be useful in several unique settings, such as studies of flow at river junctions where impacts to juvenile fish migration are significant. Additional field experiments are planned this year on the Sacramento River.
\end{abstract}

\section{INTRODUCTION}

Recently there has been considerable interest in non-contact methods for measuring river and stream flows [1]. The RiverSonde is a low-power, short-range UHF radar system operating near $435 \mathrm{MHz}$ [2] which can measure river surface velocity remotely. It uses a swept-frequency waveform for range resolution and a three-yagi antenna with direction finding for azimuth resolution [3]. Typically it is installed on a river bank, and if the flow is reasonably uniform in the channel, a single unit can provide measurements of the along-channel and cross-channel velocity profiles and mean velocity. The surface velocity measurements can be combined with bottom profile information to estimate total volumetric flow. Extended comparisons have shown excellent agreement with in-situ acoustic measurements [4].

In certain situations, more detailed information on the structure of the water flow is desired. For instance, where two river channels join, or even at a bend in a single channel, the flow patterns are likely to be quite complex. Understanding such patterns is important for studies of bank erosion, or for predicting the effect of the flow patterns on juvenile fish migration, particularly if secondary circulation exists. In order
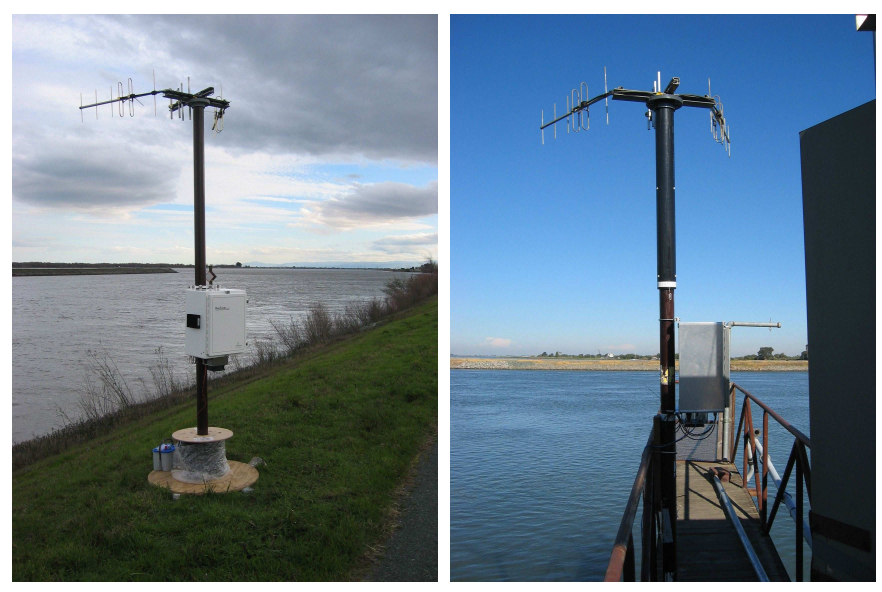

Fig. 1. RiverSonde installation at Threemile Slough. The northern unit is on the left, and the southern unit is on the right.

to evaluate the feasibility of using a pair of RiverSondes to study the two-dimensional surface velocity distribution, a pilot experiment was conducted at a site where a single RiverSonde has been in operation for several years, and additional experiments are planned in the near future.

\section{EXPERIMENT}

The experiment was conducted for 6 hours (one-half of a tidal cycle) on 21 February 2007, at Threemile Slough in Central California. The slough connects the San Joaquin and Sacramento Rivers, and at the site of the experiment it is about $200 \mathrm{~m}$ wide and runs north-south. Flow in the slough is dominated by tidal effects, with a maximum velocity of about $0.8 \mathrm{~m} / \mathrm{s}$ and flow reversals every 6 hours. The banks are straight and parallel near the site, so complicated flow patterns are expected only during flow reversals, but the site is convenient for evaluating the performance of a pair of RiverSondes and characterizing any mutual interference problems.

The two RiverSondes are shown in Fig. 1. The unit shown in the left panel was temporarily installed on the shoulder of the levee and operated from the batteries visible at the base of the antenna. The unit shown in the right panel is installed at a gaging station, on a pier which extends a few meters over the 


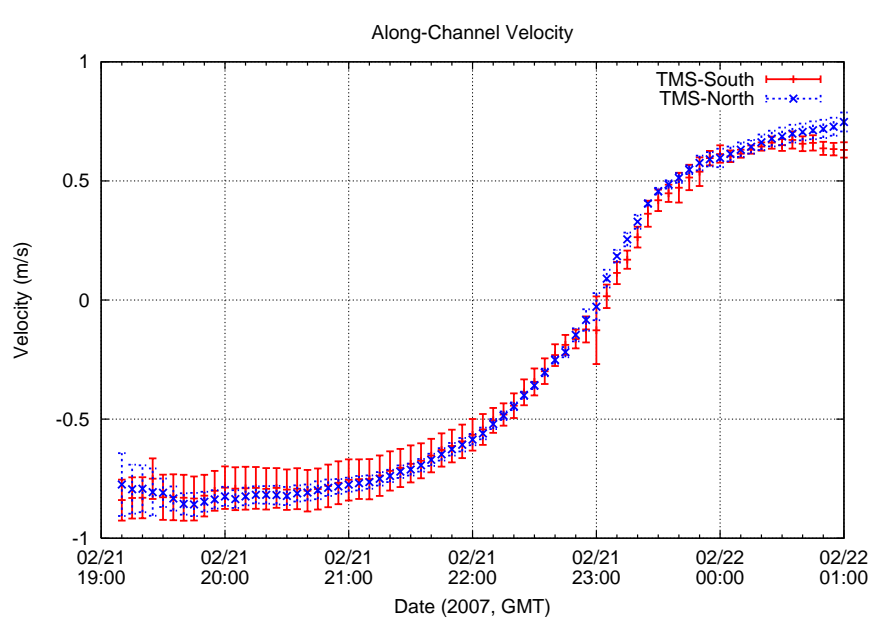

Fig. 2. Time series of the water velocity in the main channel for the 6-hour period starting at 2007-02-21 19:00 GMT. The solid red symbols represent measurements from the southern station and the dotted blue symbols are from the northern site. Positive velocity is toward the south. The error bars indicate the standard deviation of the radar observations.

water, and has been in operation for several years. The two units were about $135 \mathrm{~m}$ apart, and the two antenna arrays were directed toward the area of water between the two stations. The locations were measured with a GPS receiver, and the antenna orientations were measured using compass sightings from locations behind the individual antennas.

The antenna patterns for the two units were measured using two different techniques. The pattern for the southern unit was measured on site by rotating the antenna mast in discrete steps of 15 degrees and recording the signal from a test signal generator. The pattern for the northern unit was measured by carrying a transponder around a stationary antenna in an open field while recording both the signal from the transponder and the location of the transponder using a GPS receiver. The latter technique provided much more detailed pattern information, but time constraints prevented its use for both units.

Mutual interference between the two RiverSondes was controlled by setting them to sweep in opposite directions over the same frequency range. Each RiverSonde sweeps over $10 \mathrm{MHz}$ 16 times per second, and has a final bandwidth of about $1 \mathrm{kHz}$, so the two units "see" each other's signal for only about $0.01 \%$ of the time. It was found that there was an insignificant increase in noise level due to the presence of the second unit. This technique may be modified if more than two RiverSondes are operated in close proximity.

\section{RESULTS}

The first check was to compare the average velocity processed from the two sites independently. Figure 2 shows the along-channel velocity averaged over 40 to $120 \mathrm{~m}$ from the near shore for the two sites, using the "moving strip" method described in [4]. The error bars indicate the standard deviation of each estimate. The errors are higher for the southern site primarily because the antenna pattern for that site was not characterized as well as it was for the northern site. However,
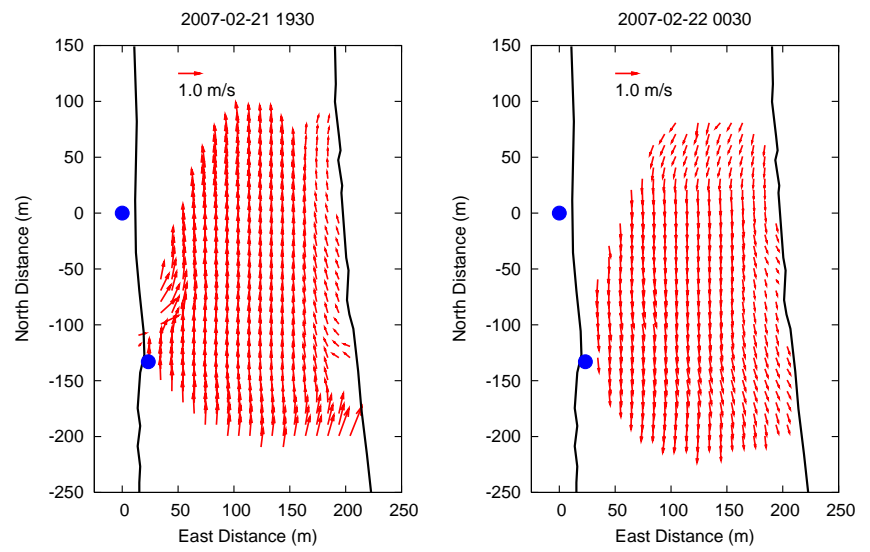

Fig. 3. Total vectors for 19:30 (left) with dominant flow toward the north and 00:30 (right) with dominant flow toward the south. The blue dots indicate the locations of the two RiverSondes.

the mean measured velocities from the two sites agree very well, giving confidence that the two units were working well together.

The next step was to combine the radial vectors from each unit into total vectors. A grid of points $10 \mathrm{~m}$ apart was established, and a total vector was computed at each grid point by combining the radial vectors falling within a $20-\mathrm{m}$ radius from each grid point. Figure 3 shows the flow pattern at 19:30, with dominant flow toward the north, and at 00:30, with dominant flow toward the south. The figures also show the banks of the channel. As expected, the flow patterns are fairly uniform and parallel to the banks, although there are some deviations from that pattern, particularly near the banks.

A more interesting flow pattern emerges near the flow reversal. Figure 4 shows the total vector field at 22:50, just before the average flow changes direction. The magnitude of the flow is smaller, although it is easily resolved (note the change in scale between Figs. 3 and 4), and a large clockwise eddy covering the entire field of view has developed. At this time, the average flow still is predominately toward the north.

Figure 5 shows the total vector field just twenty minutes later at 23:10. Now the pattern is quite chaotic, with smaller localized eddies and swirling features. These types of patterns were seen for only about 30 minutes right around the time of flow reversal, and it quickly became more organized along the direction of the banks. However, they clearly show the capability of resolving such flow patterns with paired RiverSondes. The ability to simultaneously measure the surface velocity vectors at a large number of grid points is clearly an advantage over in-situ measurements in which a single instrument must be moved to different locations in order to cover an extended area.

\section{Discussion}

Two RiverSondes have been operated simultaneously in close proximity in order to measure two-dimensional river surface velocity vectors in a water channel whose flow is tidally dominated. The two units were set up to sweep in 
2007-02-21 2250

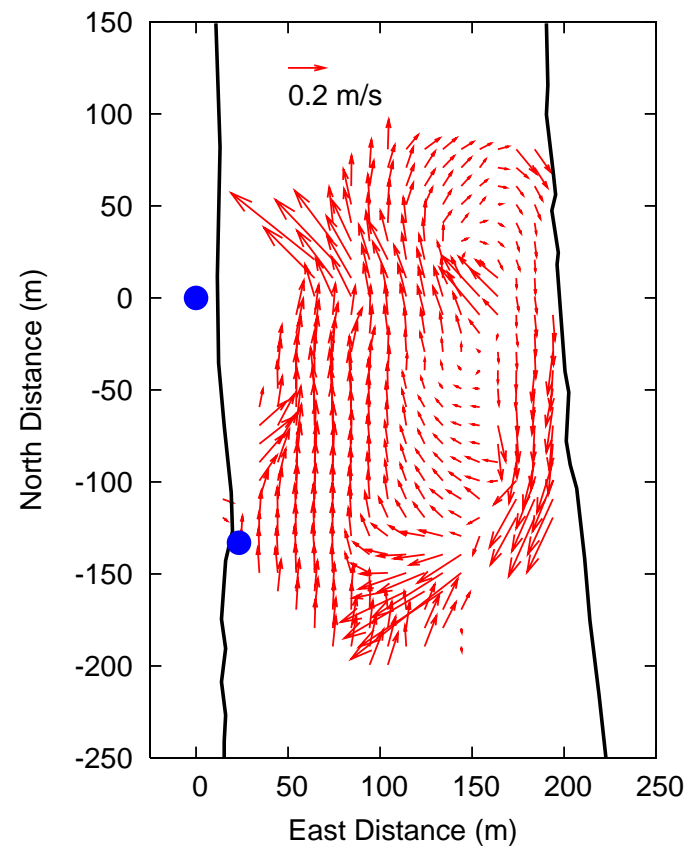

Fig. 4. Total vectors for 22:50 GMT, during flow reversal, showing a large clockwise eddy. Note the change in velocity scale from the previous plot.

opposite directions over the same frequency range, and they did not interfere with each other in this mode. Along-channel velocity estimates from each unit processed individually gave very similar results. When the data from the two units were combined, the resulting total velocity vectors showed flow parallel to the channel banks, and during the time of flow reversal complex flow patterns were clearly seen. Additional experiments are planned in the near future at two locations on the Sacramento River where two channels converge, and complex flow patterns are expected there most of the time. It is expected that the radar measurements will be quite useful for understanding the influence of such flow patterns on juvenile fish migration.

\section{ACKNOWLEDGMENT}

The authors thank Tom Lee and Chad Whelan for help in conducting the field experiments, and Hector Aguilar, Jr. and Bill Rector for help in data processing.

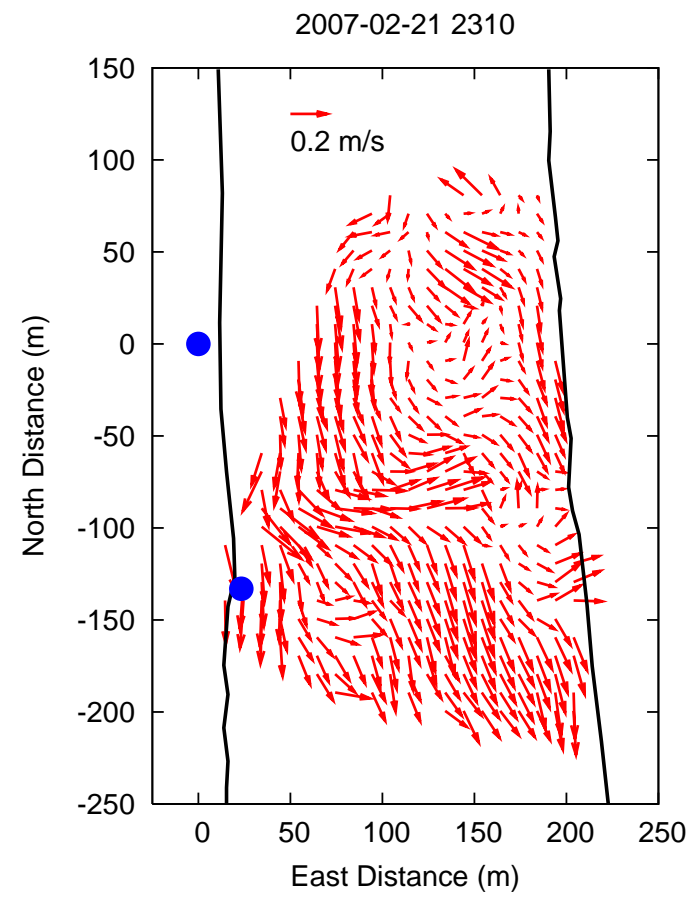

Fig. 5. Total vectors for 23:10 GMT, during flow reversal, showing flow predominately toward the south with some cross-channel flow.

\section{REFERENCES}

[1] J. E. Costa, R. T. Cheng, F. P. Hacni, N. Melcher, K. R. Spicer, E. Hayes, W. Plant, K. Hayes, C. Teague, and D. Barrick, "Use of radars to monitor stream discharge by noncontact methods," Water Resources Research, vol. 42, no. W07422, pp. 1-14, 2006.

[2] Calvin C. Teague, Donald E. Barrick, Peter M. Lilleboe, and Ralph T. Cheng, "Initial river test of a monostatic riversonde streamflow measurement system," in Proc. of the IEEE/OES Seventh Working Conference on Current Measurement Technology, Judith A. Rizoli, Ed., New York, March 2003, IEEE, pp. 46-50.

[3] Calvin C. Teague, Donald E. Barrick, Peter M. Lilleboe, and Ralph T. Cheng, "Extended UHF radar observations of river flow velocity and comparisons with in-situ measurements," in Proceedings of the Ninth International Symposium on River Sedimentation, Chunhong $\mathrm{Hu}$ and Ying Tan, Eds. October 2004, pp. 2528-2534, Tsinghua University Press, Yichang, China.

[4] Calvin C. Teague, Donald E. Barrick, Peter M. Lilleboe, Ralph T. Cheng, and Catherine A. Ruhl, "Long-term UHF RiverSonde river velocity observations at Castle Rock, Washington and Threemile Slough, California," in Proceedings of the IEEE/OES 8th Working Conference on Current Measurement Technology, New York, June 2005, pp. 85-89, IEEE. 